\title{
One Possible Cause of the Recent Increase in "Fraudulent" Research
}

\author{
Wolfgang H Vogel* \\ Retired from Department of Pharmacology, Thomas Jefferson University, USA \\ Received: 㭗 July 09, 2018; Published: 此 July 18, 2018 \\ *Corresponding author: Wolfgang H Vogel, Retired from Department of Pharmacology, Thomas Jefferson University, USA
}

\section{Opinion}

Recently, some disturbing news has shaken the scientific research community. This news reported a decline in the accuracy of research data and the more frequent appearance of wrong or even falsified research results. A survey of scientists found that $33 \%$ of scientists admitted to have fabricated, falsified or modified data or results at least once -a serious form of misconduct by any standard. Furthermore, asking about this behavior of other colleagues, admission rates for this questionable scientific activity were up to $72 \%$. Another survey screening the biomedical literature concluded that false positives and exaggerated results in peerreviewed scientific studies have reached epidemic proportions in recent years. Similarly, a review published by industrial scientists found that they could only reproduce about one quarter of all published experiments. An opinion paper by Phys.Org stated that half of biomedical research will not stand up to scrutiny and it has been estimated that about 28 billion dollars are spent per year on irreproducible research [1-7]. While deceit in research has always existed, it was at a minuscule level in the past.

Thus, the question arises, why this rapid increase in recent times. While a number of factors can be cited, the author will focus on one factor which he feels is most important in the USA where many universities and medical schools are private enterprises and faculty members are employed with various short and long term contracts. This factor is the use of research grants given to institutions and individual faculty members. These grants were established by The National Institutes of Health (NIH) to help individual researchers and institution to improve and to expand their existing research efforts. Unfortunately, this noble undertaking was soon exploited by institutions which eventually caused the decline in the quality of research performance. On a personal note, the author started his academic carrier in 1958 and obtained its first academic position at a prestigious Medical School in 1967. As the custom was at this time, he was afforded tenure as associate professor and was supplied by the institution with a laboratory, a research assistant and a budget to do research. However, it was expected that the research would result in publications but there was no pressure to do so quickly. During these times, faculty members at almost all medical institutions had tenure and were supported by their institutions to perform research.

Due to the security of their positions and continuous laboratory support, they could concentrate fully on their work and had time to repeat and to repeat their experiments over and over again. There was no pressure and no need to "falsify" experimental data. Unfortunately, the design of the research grants had a number of features which were well meant but were quickly recognized and exploited by the administration of most academic institutions to the detriment of medical research. The first feature is that the NIH allowed the researcher to receive some of his/her salary from the grant. Most institutions did not use grant money for salary support in the past. The author still remembers vividly when proudly presenting his first grant in 1969 with $30 \%$ of his salary on it to the Dean for his signature - who told the author: take the $30 \%$ off because my faculty is being paid by "hard" and not "soft" money. This changed soon and institution indirectly applied pressure to the faculty to supplement their salary more and more with grant money. The second good feature of the grant was to supplement existing institutional research support so that the researcher could expand its scientific efforts.

Again, administrations would stop soon to support the laboratories of the researchers and forced them to obtain the entire support from grants money. The third feature was that grants carried overhead intended to help the institution with the grant expanded research efforts such as, for instance, a larger animal facility. Again, in the late 80s, the author was informed that the institution would no longer offer free animal care but that he had to pay for all upkeep of his animals which costs were rising steadily over the next years. This trend affected -as my colleagues and students tell me - other institutions as well and soon became the norm. Thus, all good intentions of the NIH were turned around to the detriment of the researcher. In order to "force" the faculty to write more and larger grants, institutions abolished in most cases tenure and replaced it with yearly contracts [8]. Renewal of contracts is officially based on teaching and research efforts according to institutional handbooks but in reality is based mostly on obtaining grants to support the 
salary of the faculty member and obtain additional money for the institution. This is becoming even more severe since the number of grants awarded is now between 12 and $15 \%$.

Only grants submitted with a large number of personal publications and with a lot of unpublished "promising" data will have a chance to be funded. And such data must be obtained quickly within the grant cycle while every researcher knows that important "breakthroughs" might take time and -as history tells us might sometimes elude us for a long time or forever (The German physician Robert Koch searched vigorously all his professional life for a cure of tuberculosis - but never found it!). Breakthroughs cannot be forced they must mature through hard and tedious work and some lucky coincidences. Solid research takes time and cannot be squeezed into a rapid grant renewal cycle. Thus, many faculty members might not have the time to repeat a successful experiment a couple of times, they might be forced to select some "promising" results while "forgetting" the unsupportive data or to inflate and embellish irrelevant data in order to write a grant. While it is of course wrong to use such tactics, it is understandable that a faculty member might be tempted to do so because his professional future and the well being of his/her family depend on obtaining the next grant.

What can be done in the USA? Here are some suggestions. NIH must enforce and reinstitute some of the original intentions of the grant program. NIH must make sure that institutions again institute tenure and long term contracts so that faculty members can concentrate fully on their work. This will allow for more accurate research in that experiments can then be repeated and verified over and over again without the pressure to obtain the next grants and to stay employed. NIH must not allow termination of faculty members because of lack of grant support. NIH must force the institutions to again finance primary background research and grants can only be used to expend and enlarge existing intramural efforts. NIH must enforce that the overhead is applied in such a manner that it benefits and helps the faculty member to perform his/her research, for instance, free housing of his/her animals. My colleagues upon reading this paper will hopefully come up with more suggestions because they are the "worker bees" who suffer at present and would benefit from any changes. And finally, if institutions do not comply with these basic suggestions, they should be excluded from receiving any grant support.

\section{References}

1. (2015) Stanford researchers uncover patterns in how scientists lie about their data.

2. John PA Ioannidis (2011) An Epidemic of False Claims.

3. Greg Ip (2017) In Defense of Dismal Science.

4. http://www.the-scientist.com/?articles.list/tagNo/2644/tags/falsedata/

5. Daniele Fanelli (2009) How Many Scientists Fabricate and Falsify Research? A Systematic Review and Meta-Analysis of Survey Data.

6. (2015) Stanford researchers uncover patterns in how scientists lie about their data.

7. J Ioniddis (2011) An Epidemic of False Claims, Scientific American.

8. (2010) The Chronicle of higher Education, Medical Colleges Shrink Tenure as Their Teaching Hospitals Grow. http://www.chronicle.com/ article/Medical-Colleges-Shrink-Tenure/124105/
ISSN: 2574-1241

DOI: 10.26717/BJSTR.2018.07.001433

Wolfgang H Vogel. Biomed J Sci \& Tech Res



This work is licensed under Creative Commons Attribution 4.0 License

Submission Link: https://biomedres.us/submit-manuscript.php



